\title{
Photopolymerization of acrylates by enzymatically synthesized PCL based macrophotoinitiator
}

\author{
N. U. Kaya ${ }^{1 *}$, A. Onen ${ }^{2}$, Y. Guvenilir ${ }^{3}$ \\ ${ }^{1}$ Polymer Science \& Technology Department, Graduate School of Science Engineering \& Technology, Istanbul Technical \\ University, Maslak, 34469 Istanbul, Turkey \\ ${ }^{2}$ Chemistry Department, Faculty of Arts and Sciences, Istanbul Technical University, Maslak, 34469 Istanbul, Turkey \\ ${ }^{3}$ Chemical Engineering Department, Faculty of Chemical \& Metallurgical Engineering, Istanbul Technical University, \\ Maslak, 34469 Istanbul, Turkey
}

Received 7 December 2016; accepted in revised form 23 January 2017

\begin{abstract}
Polycaprolactone based macrophotoinitiator was synthesized via enzymatic ring-opening polymerization by using commercially available Irgacure-2959 as the nucleophilic initiator and Novozyme-435 as the immobilized lipase catalyst. The macrophotoinitiator was further utilized to photopolymerize benzyl acrylate (BzA), tetrahydrofurfurly acrylate (THFA), 2-hydroxyethyl acrylate (HEA) and poly (ethylene glycol) methyl ether acrylate $\left(M_{\mathrm{n}} \sim 480 \mathrm{~g} / \mathrm{mole}\right)$ (PEGMEA-480) under Ar atmosphere. The obtained polymers were characterized by ${ }^{1} \mathrm{H}$ Nuclear Magnetic Resonance, Fourier Transform Infrared Spectroscopy, Differential Scanning Calorimetry and Size Exclusion Chromatography. The highest dry polymer conversions were achieved with BzA and THFA. However, due to the gel formation during the photopolymerization reactions of HEA and PEGMEA-480, the dry polymer conversions were comparably lower. The photopolymerization product of BzA demonstrated a single glass transition temperature at $-6.5^{\circ} \mathrm{C}$. The enzymatically synthesized macrophotoinitiator was shown to be an efficient catalyst for light-induced polymerization of the abovementioned monomers.
\end{abstract}

Keywords: biopolymers, biocomposites, polycaprolactone, macrophotoinitiator, enzymatic polymerization, photopolymerization

\section{Introduction}

Polycaprolactone (PCL) is among the most important polymers preferred to be applied in medicine and tissue engineering owing to its mechanical properties, low melting point $\left(59-64^{\circ} \mathrm{C}\right)$, crystallinity, blend compatibility with a wide range of polymers, good solubility with biocompatibility and biodegradability by numerous bacteria [1-3]. Enzymatic polymerization is a synthetic in-vitro polymerization technique when an isolated enzyme is used as a catalyst [4]. One of the main reasons of preferring enzymatic polymerization is the residual organometallic catalysts such as $\mathrm{Zn}, \mathrm{Al}, \mathrm{Sn}, \mathrm{Sb}, \mathrm{Ti}, \mathrm{Bi}, \mathrm{Ge}$, remaining from the ring opening polymerization (ROP) of various lactones and condensation polymerization, since these metallic catalysts are intrinsically toxic limiting their usage in biomedical applications [4-6]. In addition to this, enzymatic polymerization has more prevailing features as compared with the organic synthesis such as higher catalytic activity, milder reaction conditions (i.e. temperature, pressure and $\mathrm{pH}$ etc.), better enantioselectivity, chemoselectivity and regioselectivity, and lesser by-product formation. Lactones with various ring sizes including $\varepsilon$-caprolactone (CL) are susceptible to enzymatic ring-opening polymerization (eROP) by lipases which was studied by many research groups regarding the reactivity, kinetics, selectivity, solvent and initiator effects [7].

Photopolymerization possesses a substantial interest since it has been applied in coatings, adhesives, inks,

$\overline{{ }^{*} \text { Corresponding author, e-mail: naugka12@gmail.com }}$

(C) BME-PT 
printing plates, optical waveguides and microelectronics by providing economic and environmental benefits together. For instance, photoinitiated polymerization methods might accommodate room temperature or below synthesis conditions, which is deficient in synthesis methods employing thermal energy such as thermal curing and free-radical polymer synthesis with thermally degradable initiators $[8,9]$. In the literature, benzoin, 2-hydroxy-2-methyl-1-phenyl propan-1-one (Darocure 1173), 2-hydroxy-1-[4-(2hydroxyethoxy)phenyl]-2-methyl propan-1-one (Irgacure 2959) photoinitiators were used in the synthesis of PCL based macrophotoinitiators via stannous octoate catalyzed living ring-opening polymerization (ROP) to induce photopolymerization of methyl methacrylate (MMA) resulting in block copolymers of $\varepsilon$-caprolactone (CL) and MMA [10]. Similarly, mid-chain macrophotoinitiators comprised of poly (D,L-lactide) homopolymer and tetrablock poly(D,Llactide)-poly( $\varepsilon$-caprolactone) copolymers were synthesized via ROP and they were utilized in further installation of MMA units via light induced polymerization [11].

Nucleophiles such as water and alcohols were studied in the literature for their initiation efficiency in eROP of lactones. $\omega$-unsaturated alcohols, alkyl glucopyranosides, bifunctional atom transfer radical polymerization (ATRP) initiators, are the examples of nucleophiles other than water which initiated eROP of lactones [12-17]. Irgacure-2959 (Ir2959) was used as the nucleophilic initiator to obtain a macrophotoinitiator by enzymatic ring opening polymerization (eROP) of oxacycloheptadec-10-en-2-one. The $\alpha$ Ir2959-substituted macrophotoinitiator was also UVcured [18].

The use of macrophotoinitiators might be helpful to decrease the migration of the photodecomposition products in packaging applications due to their relatively depleted mobility as compared to the smaller photoinitiators. The photodecomposition products of macrophotoinitiators also have lower volatility which might be an important feature in coating applications where low volatile organic component (VOC) content is crucial [19]. In biomedical applications such as bone cements and tooth fillings, prepolymers which bear photoactive groups are injected to obtain complex forms through small holes which overcomes the drawbacks of the surgical operations [20]. Hindering unpleasant odors, providing better solubility and compatibility are also the encouraging factors for utilizing polymeric photoinitiators [11].

Poly(benzyl acrylate) (PBzA) was preferred in the literature due to its high thermal and photochemical stability and poly(tetrahydrofurfuryl acrylate) (PTHFA) was noted with its recognizable blood compatibility $[21,22]$. Homopolymer and copolymers of 2-hydroxyethyl acrylate (HEA) were widely used in biomedical applications as a result of their hydrogel form, tunable properties and biocompatibility [23, 24]. Poly (ethylene glycol) based densely brushed polymers are well-known for their antifouling uses due to their highly efficient protein repelling feature [25].

In this study, an alternative method for the synthesis of a metal-free PCL based macrophotoinitiator via eROP unlike the polyesters including metal-catalyst residues by using Ir2959 as the nucleophilic initiator and Novozyme-435 as the immobilized lipase catalyst. Afterwards, the obtained macrophotoinitiator was used to allow light-induced polymerization of BzA, THFA, HEA and poly (ethylene glycol) methyl ether acrylate (PEGMEA-480). The macrophotoinitiator and the photopolymerization products were characterized via ${ }^{1} \mathrm{H}$ NMR, FT-IR, DSC and SEC.

\section{Experimental}

\subsection{Materials}

$\varepsilon$-Caprolactone (99\%) (CL) was purchased from Alfa Aesar, Germany. Irgacure 2959 (Ir2959) (1-[4(2-Hydroxyethoxy)-phenyl]-2-hydroxy-2-methyl-1propane-1-one) was purchased from Ciba Specialty Chemicals, Switzerland. Novozyme-435 (N435) (Candida Antarctica Lipase B immobilized on acrylic resin), poly (ethylene glycol) methyl ether acrylate (PEGMEA-480) (Average molecular weight of $480 \mathrm{~g} / \mathrm{mole}$ ) and 2-hydroxyethyl acrylate (HEA) were purchased from Sigma-Aldrich, MO, USA. Benzyl acrylate (BzA) was purchased from TCI Chemicals, Belgium. Tetrahydrofurfuryl acrylate (THFA) was purchased from Polysciences Inc., PA USA. Solvents were supplied from Sigma-Aldrich, MO, USA, and used as received.

\subsection{Methods}

\subsubsection{Characterization}

Size exclusion chromatography

Size exclusion chromatography (SEC) measurements were performed with Agilent 1100 as tetrahydrofuran (THF) was the SEC solvent with $45 \mathrm{~min}$ measurement time. 


\section{Differential scanning calorimetry}

Mettler-Toledo DSC-1, equipped with an automatic sample robot, a liquid nitrogen-based cooling system and a FRS5 sensor based on a star-shaped arrangement of 56 thermocouples was used for differential scanning calorimetry (DSC) measurements. Standard $\mathrm{Al}$ pans of $40 \mu \mathrm{L}$ were utilized for sample preparation. The DSC measurements were performed in 3 sequential runs: (1) heating from room temperature to $60^{\circ} \mathrm{C}$, (2) cooling from 60 to $-100^{\circ} \mathrm{C}$, (3) heating from -100 to $200^{\circ} \mathrm{C}$ respectively, while heating and cooling were executed in $10^{\circ} \mathrm{C} / \mathrm{min}$ ramps. Between each heating and cooling steps, isothermal periods of 5 minutes were applied. $2^{\text {nd }}$ heating curves were taken into consideration in STARe Excellence Software for the calculation of the values.

\section{Fourier transform infrared spectroscopy}

Fourier Transform Infrared Spectroscopy (FT-IR) measurements were performed with ATR-FT-IR (Affinity-1 FT-IR, Shimadzu) in the range between 600 and $4000 \mathrm{~cm}^{-1}$.

\section{${ }^{1} \mathrm{H}$ nuclear magnetic resonance}

${ }^{1} \mathrm{H}$ Nuclear Magnetic Resonance (NMR) measurements were performed with Agilent VNMRS $500 \mathrm{MHz}\left(\mathrm{CDCl}_{3}\right)$.

\subsubsection{Enzymatic synthesis of PCL-based macrophotoinitiato}

The eROP mechanism of CL as N435 was the enzymatic catalyst and Ir2959 the nucleophilic initiator was demonstrated in Figure 1. For the enzymatic synthesis of PCL-based macrophotoinitiator, firstly, Ir2959 was dissolved in CL at room temperature and the mixture was treated with freshly activated $4 \AA$ molecular sieves for two days. N435 (200 mg) was dried at $50^{\circ} \mathrm{C}$ for 3 days in a vacuum oven; the glass reactor was treated with flame under vacuum and closed with rubber septum. Monomer/initiator mixture was added via syringe to the reactor and the reaction proceeded for 8 hours at $80^{\circ} \mathrm{C}$. CL/initiator ratio (mole/mole) was 10 and the total mixture of the monomer and the initiator was $4.5 \mathrm{~g}$. The reaction was stopped by adding chloroform and enzyme was filtered. Excess chloroform was evaporated from the mixture and the polymer was precipitated via icecold methanol for 4 times. The resulting polymer was washed with methanol to ensure the successful removal of the unreacted Ir2959 from the macrophotoinitiator. Sequentially, the polymer was dried under vacuum at $30^{\circ} \mathrm{C}$ for 4 days.

\subsubsection{Photopolymerization reactions initiated by PCL based macrophotoinitiator}

Light Emitting Diode (LED) lamps with 360-400 nm wavelength emission were utilized. $15^{\circ}$ of optical

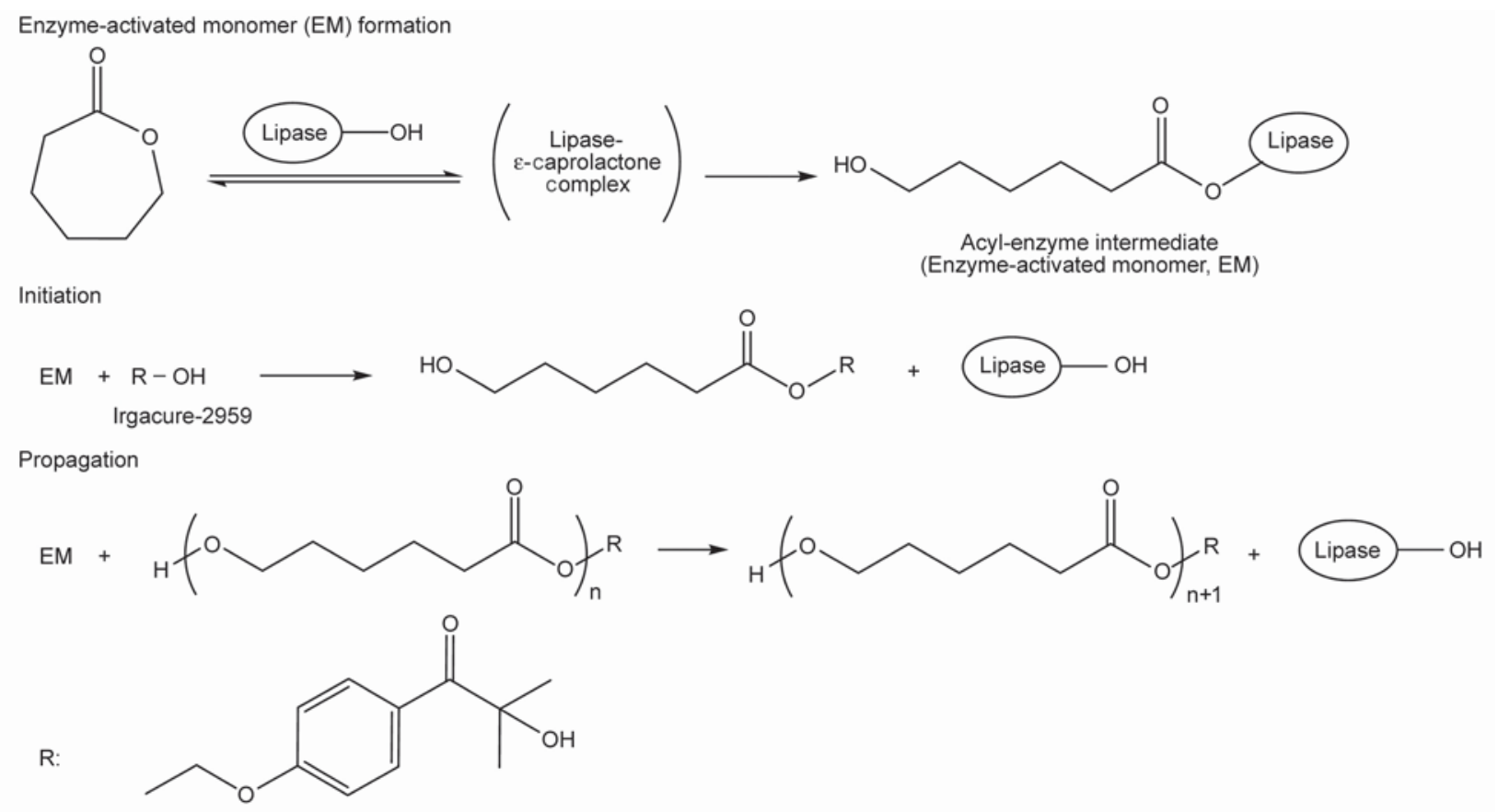

Figure 1. Enzymatic ring-opening polymerization mechanism of CL with lipase as Ir2959 was the initiator [4] 
lenses were used for effective focusing to the reaction mixtures. The advantage of the LED lamps is the ignorable heating of the reaction medium, consequently prevention of the solvent evaporation and pressure build-up and loss of solvent from the reaction medium. PCL based macrophotoinitiator, acrylic monomer, magnetic stirring bar and $0.4 \mathrm{~mL}$ of dimethylacetamide (DMA) were put into a $10 \mathrm{~mL}$ snapcapped glass vial. The vial was purged with Ar gas. The mixture was kept at $35^{\circ} \mathrm{C}$ for $2-3 \mathrm{~min}$ and subsequently in ultrasonic bath again for 2-3 $\mathrm{min}$ to ensure good solubility of the compounds in the solvent. Then UV polymerization was started; the reaction time was kept as 20 minutes for each monomer. The amount of the macrophotoinitiator was $40 \mathrm{mg}$, the ratio of acrylate/macrophotoinitiator (mole/mole) was kept constant at 200 in all of the photopolymerization experiments.

The resulting polymers were dissolved in chloroform when BzA and THFA were used as monomers and precipitated in ice cold diethyl ether for two times. However, since gel formation observed when HEA and PEGMEA-480 were used as monomers, it was not possible to dissolve the gels in chloroform, dichloromethane, dimethylacetamide, dimethylsulfoxide, toluene and tetrahydrofurane. Hence, the gels were rinsed with chloroform and ice-cold methanol respectively in order to remove the residual macrophotoinitiator, PEGMEA-480, HEA and DMA trapped inside the gels. The rinsed polymers were dried under vacuum oven at $40^{\circ} \mathrm{C}$ for 2 days.

\section{Results and discussion}

${ }^{1} \mathrm{H}$ NMR spectrum of the Ir2959 end-functionalized PCL based macrophotoinitiator was demonstrated in Figure 2. The characteristic peaks of the structure were as follows: $\delta=7.90-7.95 \mathrm{ppm}\left(2 \mathrm{H}, \mathrm{m}, \boldsymbol{H}_{\mathrm{a}}\right) ; \delta=$ 6.93-6.98 ppm $\left(2 \mathrm{H}, \mathrm{m}, \boldsymbol{H}_{\mathbf{b}}\right) ; \delta=4.43-4.47 \mathrm{ppm}(2 \mathrm{H}$, $\left.\mathrm{t}, \boldsymbol{H}_{\mathbf{d}}\right) ; \delta=4.23-4.27 \mathrm{ppm}\left(2 \mathrm{H}, \mathrm{t}, \boldsymbol{H}_{\mathbf{c}}\right) ; \delta=4.00$ $4.15 \mathrm{ppm}\left(2 \mathrm{H}, \mathrm{t}, \boldsymbol{H}_{\mathbf{5}}\right) ; \delta=3.61-3.67 \mathrm{ppm}\left(2 \mathrm{H}, \mathrm{t}, \boldsymbol{H}_{\mathbf{5}^{\prime}}\right)$; $\delta=2.23-2.38 \mathrm{ppm}\left(2 \mathrm{H}, \mathrm{t}, \boldsymbol{H}_{1}\right) ; \delta=1.50-1.75 \mathrm{ppm}$ $\left(4 \mathrm{H}, \mathrm{m}, \boldsymbol{H}_{\mathbf{2}}, \boldsymbol{H}_{\mathbf{4}}\right) ; \delta=1.64 \mathrm{ppm}\left(6 \mathrm{H}, \mathrm{s}, \boldsymbol{H}_{\mathbf{e}}\right) ; \delta=1.30$ $1.45 \mathrm{ppm}\left(2 \mathrm{H}, \mathrm{t}, \boldsymbol{H}_{\mathbf{3}}\right)$. The end-group fidelity of the macrophotoinitiator was found according to the Equation (1), where $I_{\mathrm{d}}$ and $I_{5^{\prime}}$ were the peak integrals of the peaks $\mathbf{d}$ and $\mathbf{5}^{\prime}$ respectively. The peak $\mathbf{5}^{\prime}$ presented in every polymer chain as the $-\mathrm{CH}_{2}-$ neighboring the chain-end hydroxyl group; while the peak d only presented in the successfully Ir2959 end-functionalized PCL chains. The end-group fidelity (the molar ratio of Ir2959 end-functionalized PCL chains to the total PCL chains in the dry polymer mixture) was calculated as the direct ratios of the peak areas of these two peaks. The molecular weight of the
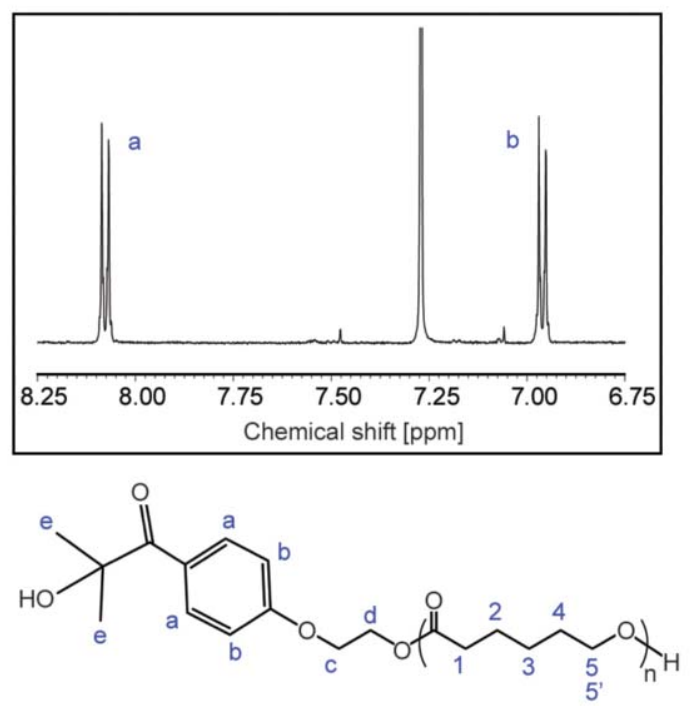

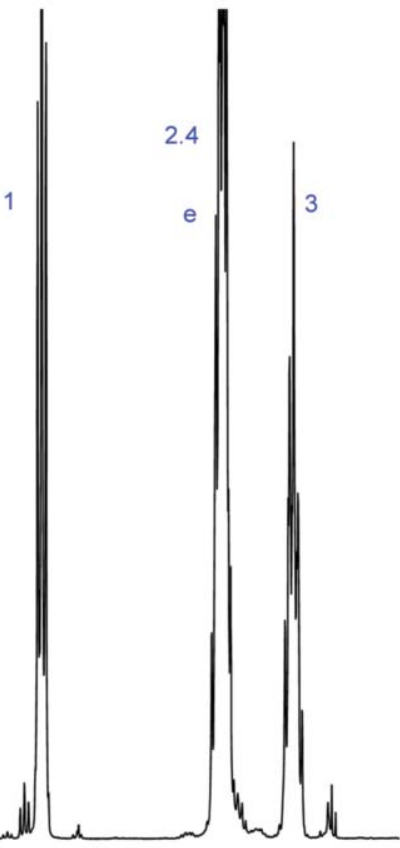

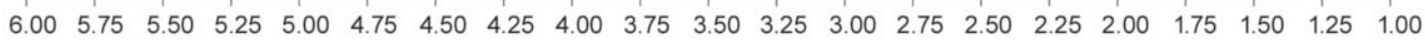

Chemical shift [ppm]

Figure 2. ${ }^{1} \mathrm{H}$ NMR of the PCL based macrophotoinitiator 
macrophotoinitiator was calculated as $3875 \mathrm{~g} / \mathrm{mole}$ according to ${ }^{1} \mathrm{H}$ NMR result. On the other hand, the $M_{\mathrm{n}}$ value was calculated as $5150 \mathrm{~g} / \mathrm{mole}$ from the SEC results. The dry polymer conversion was found as $52 \%$ and the end-group fidelity was calculated as 93\% according to Equation (1):

End-group fidelity $=\frac{I_{\mathrm{d}}}{I_{5^{\prime}}}$

${ }^{1} \mathrm{H}$ NMR spectrum of the PCL- $b$-PBzA was shown in Figure 3. The characteristic peaks of the structure were as follows: $\delta=7.90-7.95 \mathrm{ppm}\left(2 \mathrm{H}, \mathrm{m}, \boldsymbol{H}_{\mathbf{a}}\right) ; \delta=$ 7.11-7.38 ppm (5H, m, $\left.\boldsymbol{H}_{\mathbf{A}}, \boldsymbol{H}_{\mathbf{B}}, \boldsymbol{H}_{\mathbf{C}}\right) ; \delta=6.93-$ $6.98 \mathrm{ppm}\left(2 \mathrm{H}, \mathrm{m}, \boldsymbol{H}_{\mathbf{b}}\right) ; \delta=4.82-5.06\left(2 \mathrm{H}, \mathrm{s}, \boldsymbol{H}_{\mathrm{D}}\right)$; $\delta=4.43-4.47 \mathrm{ppm}\left(2 \mathrm{H}, \mathrm{t}, \boldsymbol{H}_{\mathrm{d}}\right) ; \delta=4.23-4.27 \mathrm{ppm}$ $\left(2 \mathrm{H}, \mathrm{t}, \boldsymbol{H}_{\mathbf{c}}\right) ; \delta=4.00-4.15 \mathrm{ppm}\left(2 \mathrm{H}, \mathrm{t}, \boldsymbol{H}_{5}\right) ; \delta=3.61-$ $3.67 \mathrm{ppm}\left(2 \mathrm{H}, \mathrm{t}, \boldsymbol{H}_{\mathbf{5}^{\prime}}\right) ; \boldsymbol{\delta}=2.23-2.38 \mathrm{ppm}\left(2 \mathrm{H}, \mathrm{t}, \boldsymbol{H}_{\mathbf{1}}\right)$; $\delta=1.78-1.99 \mathrm{ppm}\left(1 \mathrm{H}, \mathrm{b}, \boldsymbol{H}_{\mathbf{G}}\right) ; \delta=1.50-1.75 \mathrm{ppm}$ $\left(6 \mathrm{H}, \mathrm{m}, \boldsymbol{H}_{\mathbf{2}}, \boldsymbol{H}_{\mathbf{4}}, \boldsymbol{H}_{\mathbf{H}}\right) ; \delta=1.30-1.45 \mathrm{ppm}\left(2 \mathrm{H}, \mathrm{t}, \boldsymbol{H}_{\mathbf{3}}\right)$. According to the ${ }^{1} \mathrm{H}$ NMR of the purified dry polymer of this reaction Figure 3, the conversion was calculated as $93 \%$ confirming the conversion calculation from the crude reaction mixture, where $[I]_{D}^{\mathrm{d}}$ and $[I]_{5}^{\mathrm{d}}$ were the peak integrals of the peaks $\boldsymbol{D}$ and $\mathbf{5}$ of the dry polymer and $[I]_{\mathrm{D}^{\prime}}^{\mathrm{f}}$ and $[I]_{5}^{\mathrm{f}}$ were the peak integrals of the peaks $\boldsymbol{D}^{\prime}$ and $\mathbf{5}$ of the feed before photopolymerization Equation (2). The molar feed ratio of the benzyl acrylate monomer to the CL repeating units in the macrophotoinitiator before the light induced polymerization was 200/31 (mole/mole):

Dry polymer conversion benzyl acrylate [\%] =

$$
=\frac{\frac{[I]_{\mathrm{D}}^{\mathrm{d}}}{[I]_{5}^{\mathrm{d}}}}{\frac{[I]_{\mathrm{D}^{\prime}}^{\mathrm{f}}}{[I]_{5}^{\mathrm{f}}}} \cdot 100
$$

${ }^{1} \mathrm{H}$ NMR spectrum of the product obtained via photopolymerization THFA as Ir2959 end-functionalized PCL was the macrophotoinitiator was shown in Figure 4 . The characteristic peaks of the structure were as follows: $\delta=4.23-4.27 \mathrm{ppm}\left(2 \mathrm{H}, \mathrm{t}, \boldsymbol{H}_{\mathbf{c}}\right) ; \delta=$ 3.93-4.17 ppm (5H, $\left.\boldsymbol{H}_{\mathbf{5}}, \boldsymbol{H}_{\mathrm{D}}, \boldsymbol{H}_{\mathrm{E}}\right) ; \delta=3.69-3.91 \mathrm{ppm}$ $\left(2 \mathrm{H}, \mathrm{m}, \boldsymbol{H}_{\mathrm{A}}\right) ; \delta=2.23-2.53 \mathrm{ppm}\left(3 \mathrm{H}, \boldsymbol{H}_{\mathbf{1}}, \boldsymbol{H}_{\mathbf{F}}\right) ; \delta=$ 1.78-2.07 ppm (3H, m, $\left.\boldsymbol{H}_{\mathbf{B} 1}, \boldsymbol{H}_{\mathbf{B} 2}, \boldsymbol{H}_{\mathbf{C} 1}\right) ; \delta=1.45-$ $1.78 \mathrm{ppm}\left(7 \mathrm{H}, \boldsymbol{H}_{\mathbf{G}}, \boldsymbol{H}_{\mathbf{C} 2}, \boldsymbol{H}_{\mathbf{2}}, \boldsymbol{H}_{\mathbf{4}}\right) ; \delta=1.30-1.45 \mathrm{ppm}$ $\left(2 \mathrm{H}, \mathrm{t}, \boldsymbol{H}_{\mathbf{3}}\right)$. The dry polymer conversion was calculated

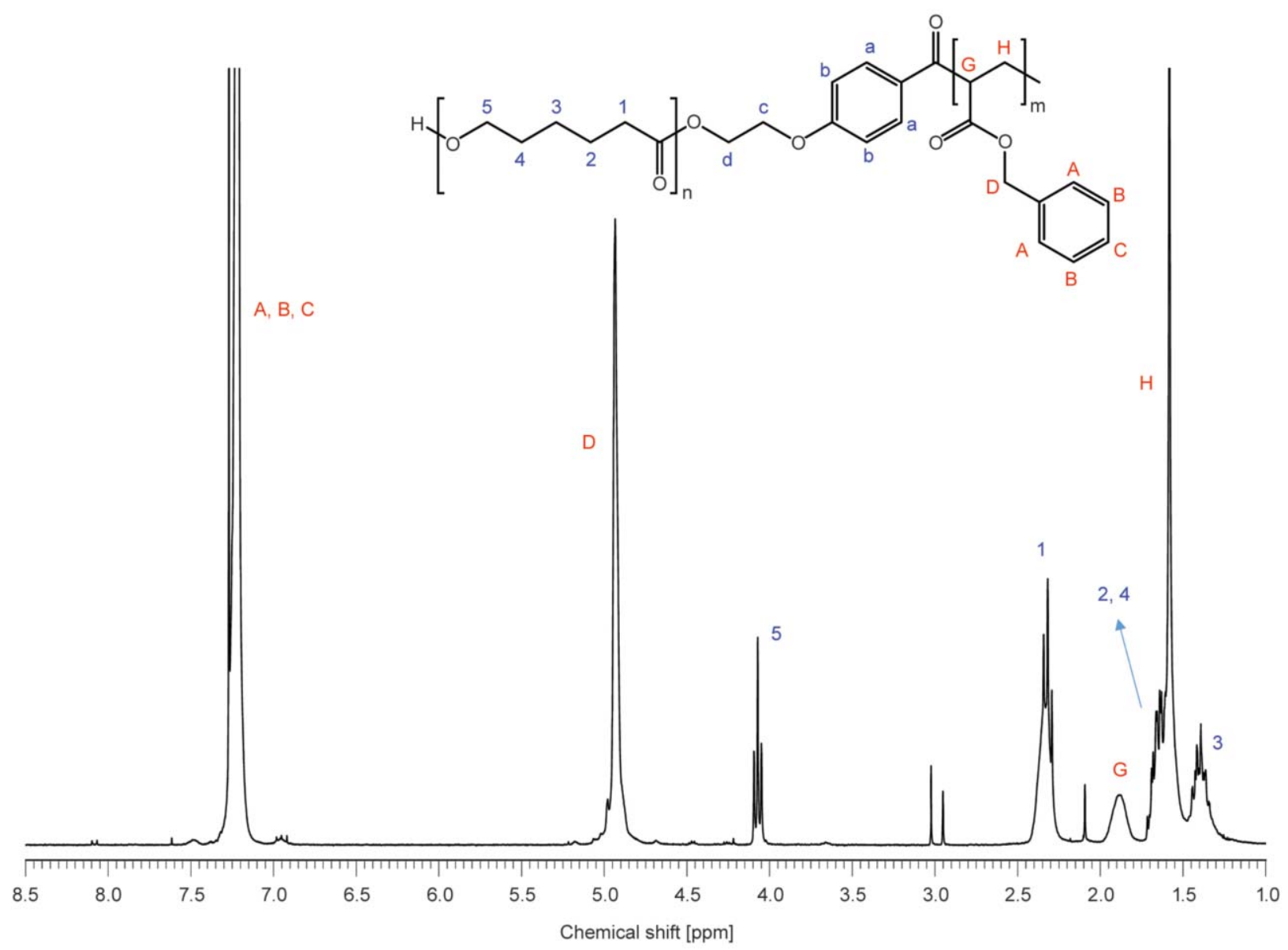

Figure 3. ${ }^{1} \mathrm{H}$ NMR of the product synthesized via photopolymerization of BzA by PCL based macrophotoinitiator 


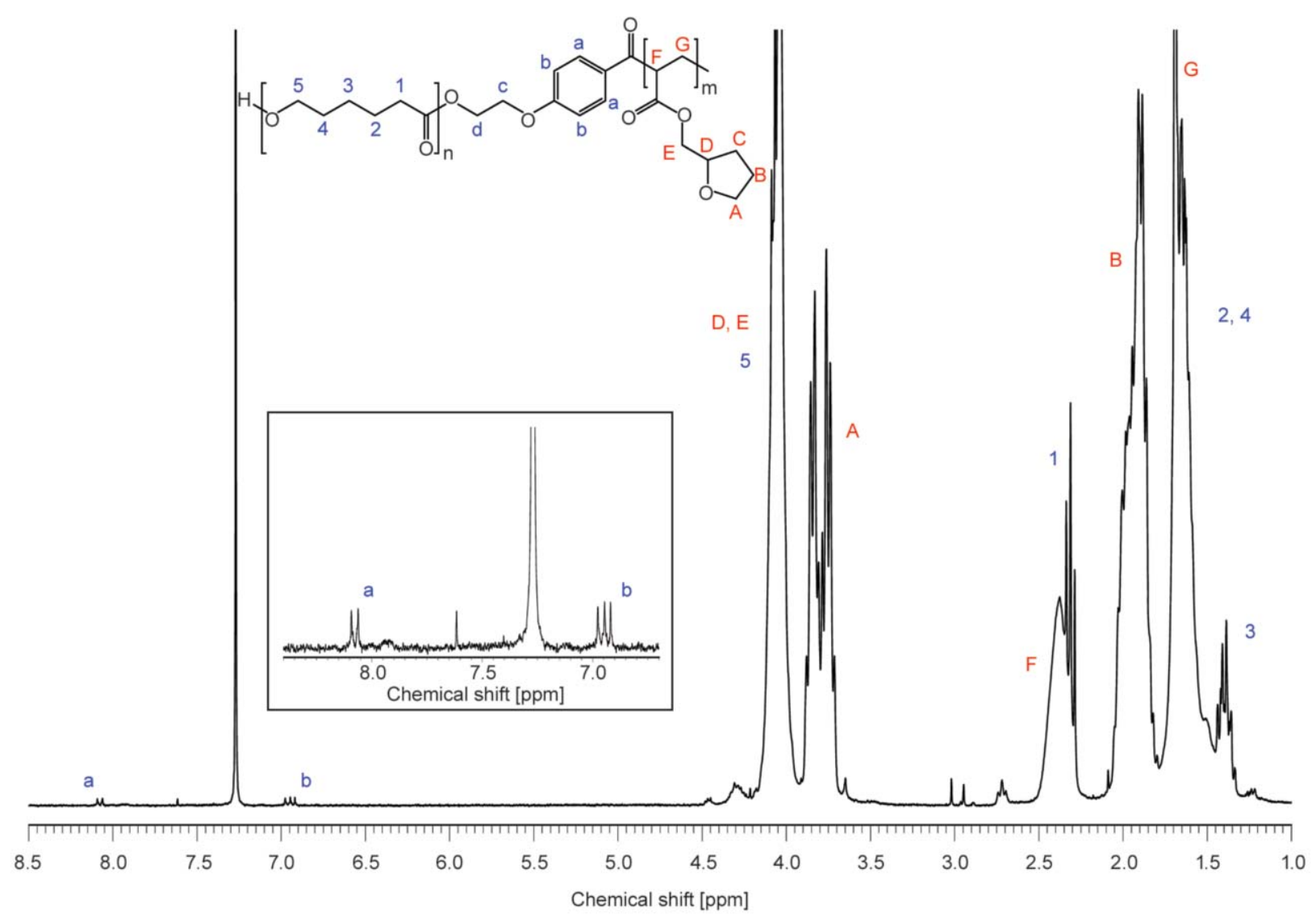

Figure 4. ${ }^{1} \mathrm{H}$ NMR of the product synthesized via photopolymerization of THFA by PCL based macrophotoinitiator

following Equations (3)-(5). $m / n$ referred to the ratio of the number of the repeating units of THFA to the repeating units of $\mathrm{CL}$ in the macrophotoinitiator which was calculated according to Equation (4) and (5). $I_{\mathrm{A}}, I_{\mathrm{D}}, I_{\mathrm{E}}$ and $I_{5}$ and were the integral values of the peaks $\mathbf{A}, \mathbf{D}, \mathbf{E}$ and $\mathbf{5}$ respectively. $\left(m_{\text {feed }}\right) /\left(n_{\text {feed }}\right)$ was the feed molar ratio of the THFA monomer to the $\mathrm{CL}$ repeating units in the macrophotoinitiator before the light induced polymerization, which was the same as BzA photopolymerization, 200/31 (mole/ mole):

Dry polymer conversion of THFA [\%] $=\frac{\frac{m}{n}}{\frac{\left(m_{\text {feed }}\right)}{\left(n_{\text {feed }}\right)}}$

$I_{\mathrm{D}}+I_{\mathrm{E}}+I_{5}=3 m+2 n$

$I_{\mathrm{A}}=2 n$

The ${ }^{1} \mathrm{H}$ NMR of the photopolymerization product of HEA and PEGMEA-480 macromonomer couldn't be measured due to the insolubility of the resulting polymers in solvents such as, dichloromethane, dimethylformamide, dimethylsulfoxide, N,N-dimethylacetamide, toluene, hexane, acetonitrile and water.
Therefore only DSC and FT-IR measurements of the resulting gels could be executed. The chemical structure of the target block copolymer, PCL- $b$-PHEA was shown in Figure 5.

The FT-IR spectra of Ir2959 end-functionalized PCL based macrophotoinitiator and the polymer obtained after photopolymerization of HEA were shown in Figure 6. In both of the spectrums, asymmetric stretching of $\mathrm{CH}_{2}$, symmetric stretching of $\mathrm{CH}_{2}, \mathrm{C}=\mathrm{O}$ carbonyl stretching and symmetric $\mathrm{C}-\mathrm{O}-\mathrm{C}$ stretching at $2945,2864,1720$ and $1165 \mathrm{~cm}^{-1}$ respectively were the common peaks remained the same after photopolymerization. On the other hand, after polymerization of HEA, the appearance of an $\mathrm{O}-\mathrm{H}$ stretching region around $3000-3700 \mathrm{~cm}^{-1}$ together with $\mathrm{O}-\mathrm{H}$ bending at $1073 \mathrm{~cm}^{-1}$ were attributed the

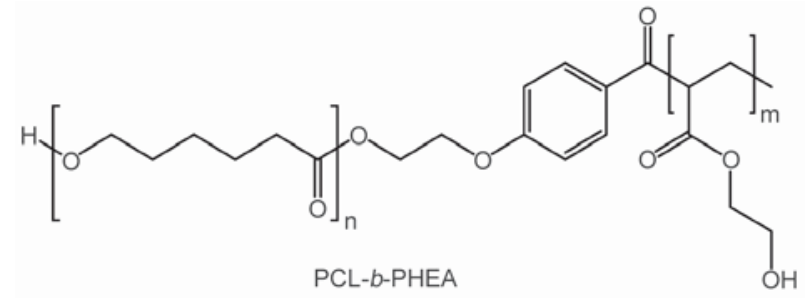

Figure 5. Chemical structure of the target block copolymer PCL- $b$-PHEA 


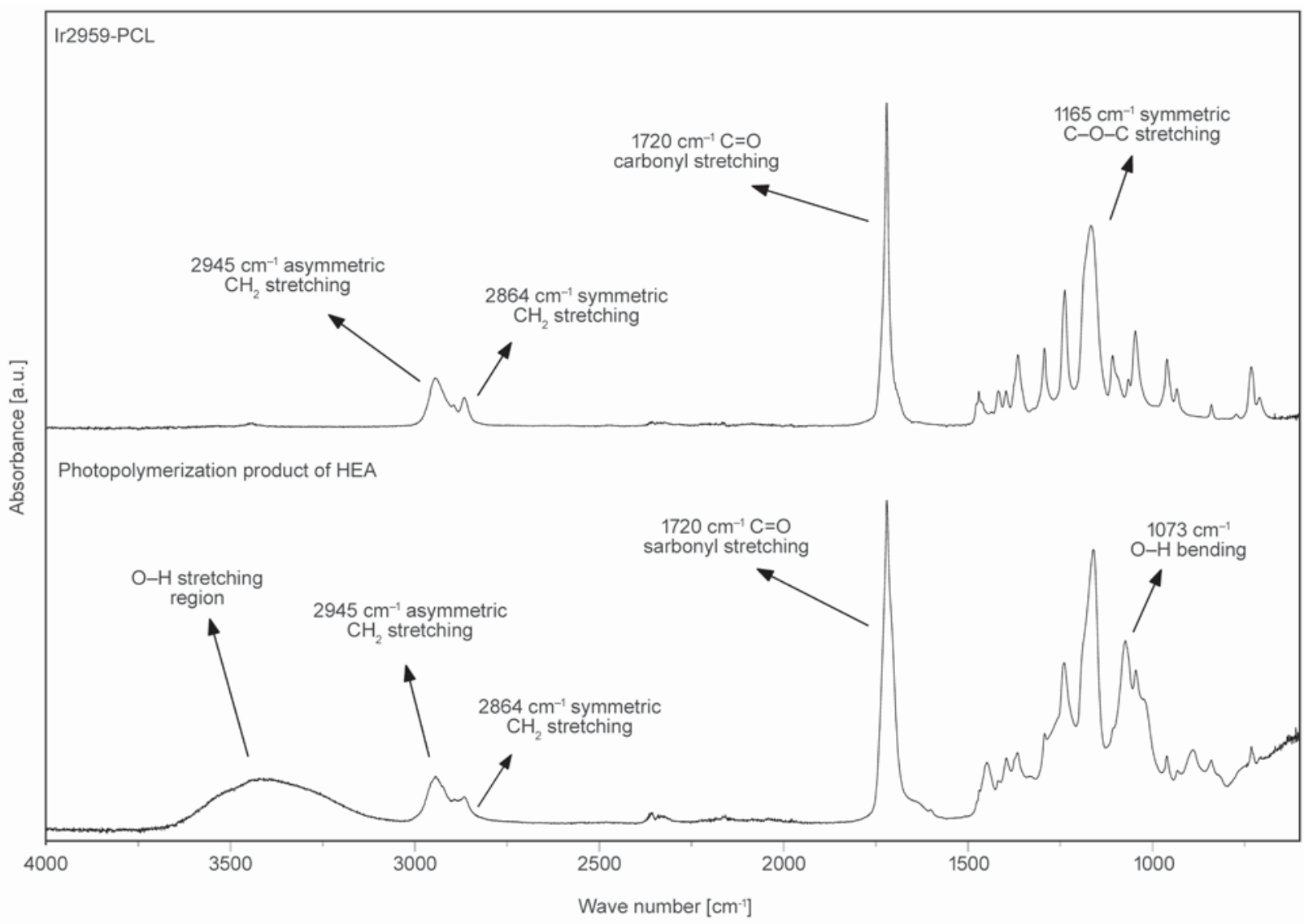

Figure 6. FT-IR spectrum of the PCL based macrophotoinitiator and the gel obtained after photopolymerization of HEA

HEA repeating units confirming the hydrogen bonds occurred chiefly driven by the $-\mathrm{OH}$ functionalities. However, FT-IR technique is not sufficient enough to reveal whether the resulting polymer was a mixture of polymers or a block copolymer as well as ${ }^{1} \mathrm{H}$ NMR.

The chemical structure of the target block copolymer after photopolymerization of PEGMEA-480 macromonomer by the PCL based macrophotoinitiator was demonstrated in Figure 7. In the FT-IR spectrum of photopolymerization product of PEGMEA-480, it can be seen that after the photopolymerization of PEGMEA-480, the resulting polymer had a slight wide $\mathrm{O}-\mathrm{H}$ stretching region between $3000-3700 \mathrm{~cm}^{-1}$, which was attributed to the moisture uptake of the PEGMEA-480 segments in the final polymer due to the nature of PEG even though the PEGMEA-480 macromonomer was not containing hydroxyl endgroups. All of the other peaks related to PCL structure were the same as asymmetric stretching at $2945 \mathrm{~cm}^{-1}$, symmetric stretching at $2864 \mathrm{~cm}^{-1}$, carbonyl stretching at $1720 \mathrm{~cm}^{-1}$ and $\mathrm{C}-\mathrm{O}-\mathrm{C}$ stretching at $1165 \mathrm{~cm}^{-1}$. Additionally, the peak with small aborbance at $1637 \mathrm{~cm}^{-1}$ was associated with the double bonds of the unreacted PEGMEA-480 macromonomer residue trapped

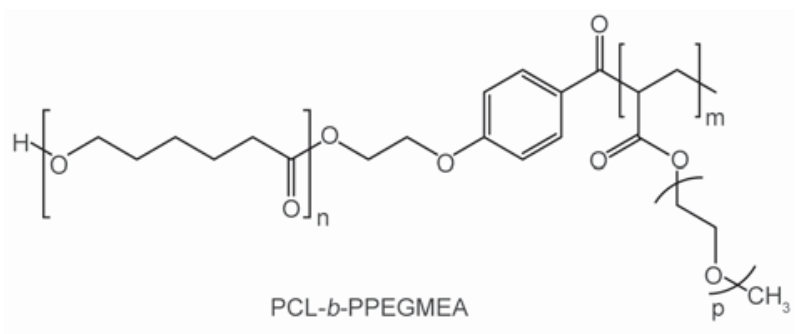

Figure 7. Chemical structure of the target block copolymer PCL- $b$-PPEGMEA

inside the gel, despite the resulting gel was rinsed with chloroform numerous times. The peak with highest absorbance value at $1099 \mathrm{~cm}^{-1}$, which was the result of $\mathrm{C}-\mathrm{O}, \mathrm{C}-\mathrm{C}$ stretching together with $\mathrm{C}-\mathrm{H}$ rocking (trans) vibrations, implied the PEGMEA480 segments in the resulting polymer (Figure 8).

In Figure 9, the $2^{\text {nd }}$ heating curves on the DSC thermograms of the macrophotoinitiator and the photopolymerization products of BzA, THFA, HEA and PEGMEA-480 were demonstrated. For the photopolymerization reaction when BzA was the monomer, the only endothermic transition was the broad and high step change glass transition of the resulting polymer. The $T_{\mathrm{g}}$ of the polymer was evaluated as $-6.5^{\circ} \mathrm{C}$. Thus, the resulting polymer had a completely amorphous 
structure. Since there was a only one glass transition observed, the resulting polymer might be the block copolymer of PCL and PBzA. On the other hand, the polymer might also be the homogeneously mixed block copolymer, unreacted PCL chains and the homopolymer of PBzA, since two different free radicals occured during the photodecomposition of the macrophotoinitiator one of which was including the PCL chain and the other was the ketyl radical. For photopolymerization of THFA, the broad and high step change in the glass transition of the polymer with an onset value of $-12.2{ }^{\circ} \mathrm{C}$ revealed the amorphous domains in the photopolymerization product. Interestingly, the glass transition of the macrophotoinitiator at $-53.3^{\circ} \mathrm{C}$ couldn't be observed. The two melting points at closed values to each other were observed $\left(52.4\right.$ and $\left.56.7^{\circ} \mathrm{C}\right)$ was an indication of two different crystalline domains. The melting at $52.4^{\circ} \mathrm{C}$ was attributed to the unreacted PCL chains and the melting at $56.7^{\circ} \mathrm{C}$ was associated with either the block copolymer or the mixture of block copolymer with the homopolymer of THFA.

For the photopolymerization of HEA, since there were two distinct glass transitions (at -55.3 and $16.5^{\circ} \mathrm{C}$ ) and two melting peaks (at $55.9^{\circ} \mathrm{C}$ and a broad peak around $160^{\circ} \mathrm{C}$ ) were observed, the resulting polymer might be evaluated as the mixture of the unreacted PCL, homopolymer of HEA and the block copolymer PCL- $b$-PHEA. The $T_{\mathrm{g}}$ value at $-55.3^{\circ} \mathrm{C}$ and $T_{\mathrm{m}}$ value at $55.9^{\circ} \mathrm{C}$ were the characteristic peaks of the PCL based macrophotoinitiator. On the other hand, the broad and highly inclined $T_{\mathrm{g}}$ value at $16.5^{\circ} \mathrm{C}$ was ascribed to the block copolymer and/or the homopolymer of HEA. Therefore, the photopolymerization product was in the rubbery state and had an elastic behavior. The broad endothermic transition around $160^{\circ} \mathrm{C}$ was due to the high melting point of HEA including polymer chains equipped with dense hydrogen bonds due to the hydroxyl functionality of HEA repeating units, which was also confirmed by FT-IR measurements. For the photopolymerization reaction of PEGMEA-480, the only one glass transition $\left(\right.$ at $\left.-61.2^{\circ} \mathrm{C}\right)$ temperature was attributed to either the homo-brush polymer of PEGMEA-480 macromonomer, or the block copolymer PCL- $b$-PPEGMEA-480. Additionally, there were two melting transitions (a peak at $6.6{ }^{\circ} \mathrm{C}$ and a small peak with multiple shoulders around $54^{\circ} \mathrm{C}$ ) were observed.

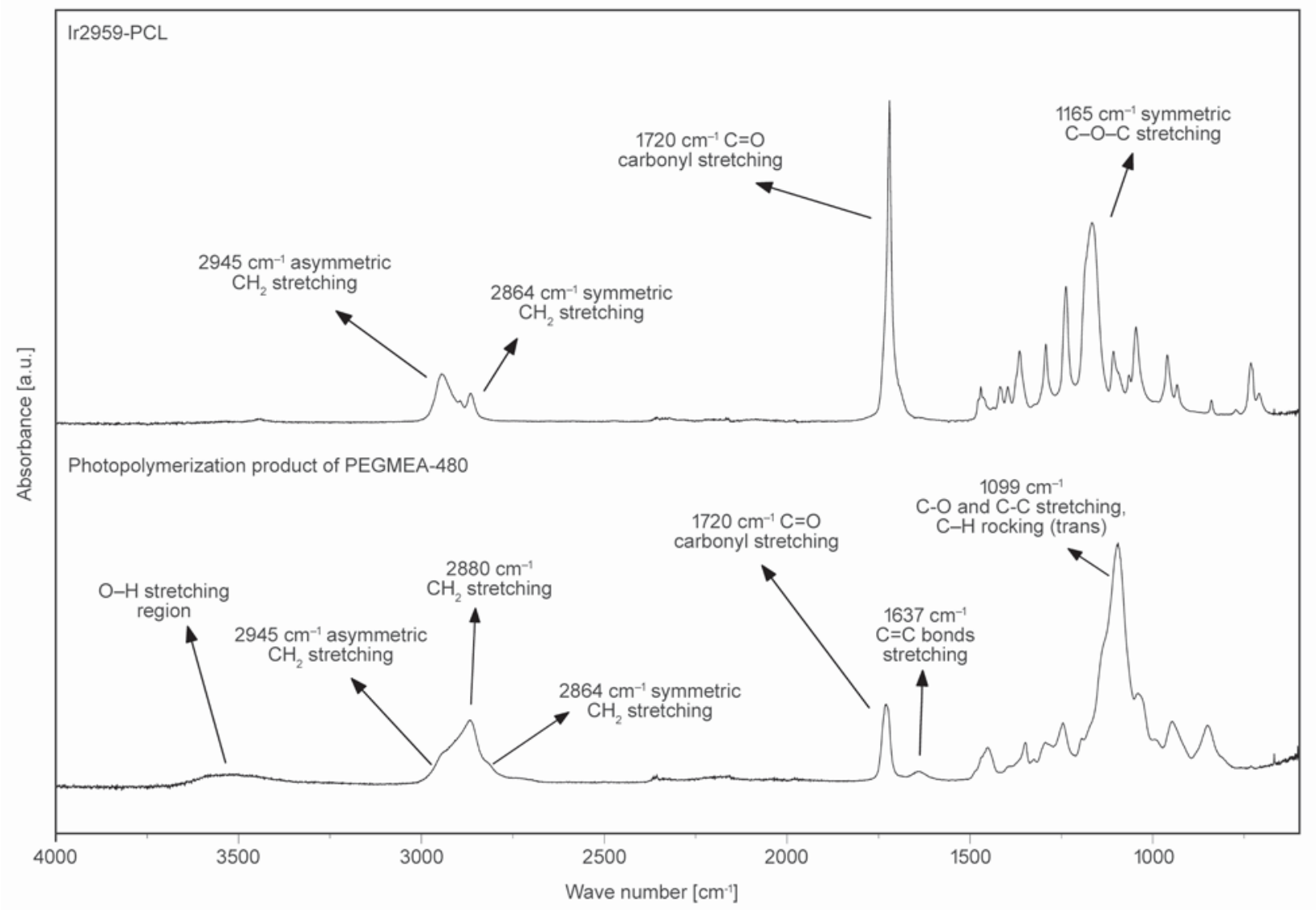

Figure 8. FT-IR spectrum of the PCL based macrophotoinitiator and the gel obtained after photopolymerization of PEGMEA-480 
The $T_{\mathrm{m}}$ at $54^{\circ} \mathrm{C}$ was considered as the residual unreacted PCL chains, and the $T_{\mathrm{m}}$ at $6.6^{\circ} \mathrm{C}$ as the melting of the block copolymer. The low $T_{\mathrm{g}}$ and $T_{\mathrm{m}}$ values signified the rubbery and elastic state of the resulting polymer similar to the photopolymerization products conducted with the other monomers.

SEC results of the photopolymerization reactions performed by using BzA, THFA and PCL-based macrophotoinitiator were demonstrated in Figure 10. The PCL-based macrophotoinitiator had a PDI value of 1.46 and $M_{\mathrm{n}}$ of $5150 \mathrm{~g} /$ moles calculated from SEC measurement. There are two free-radicals forming due to photoactivation of Ir2959: (a) the radical

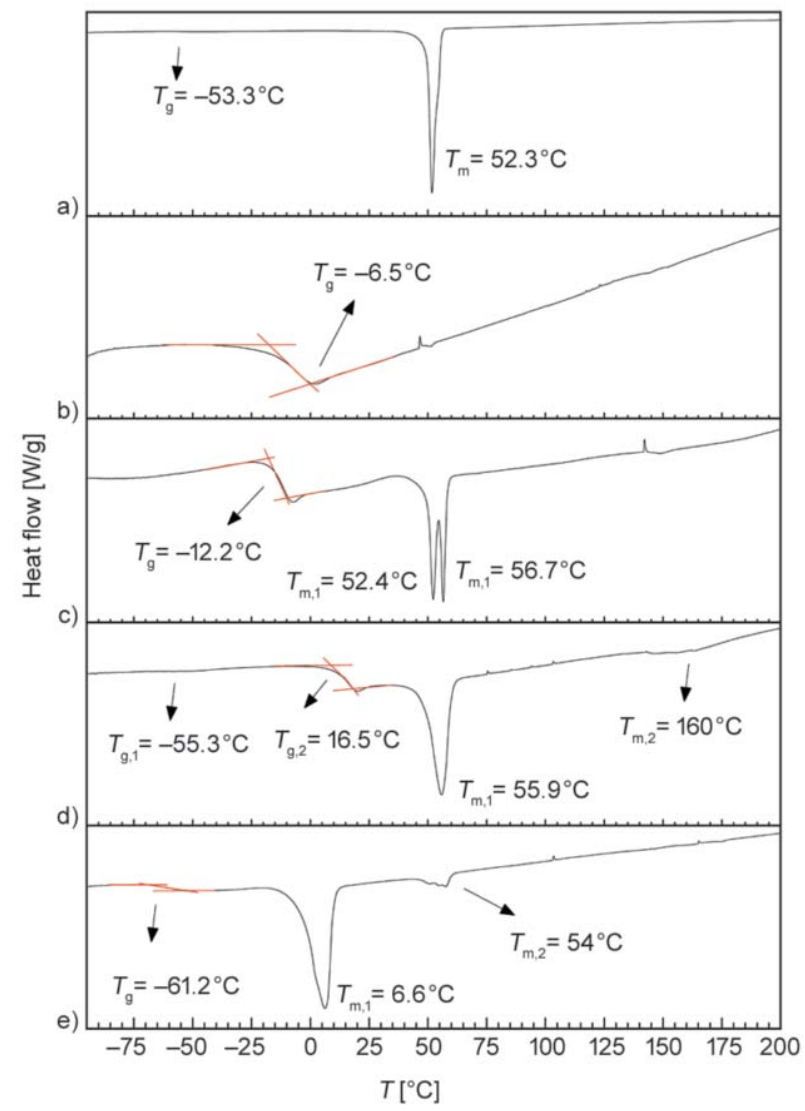

Figure 9. DSC $2^{\text {nd }}$ heating curves of (a) PCL based macrophotoinitiator and the photopolymerization products of (b) BzA, (c) THFA, (d) HEA, (e) PEGMEA-480 bearing the benzyl group and the PCL chain, (b) the ketyl radical. Both radicals may initiate the photopolymerization reactions of (meth)acrylates [26]. Hence, it was possible to obtain the homopolymers of the acrylates inside the photopolymerization products initiated by the ketyl radical. In the polymerization performed with THFA, there was a wide peak comprising three shoulders all of which shifted to higher molecular weight values as compared with the macrophotoinitiator. The SEC curve of the product of the experiment conducted with BzA, had a smoother curve than THFA. BzA photopolymerization had also two other molecular weight distributions considering the slightly recognizable shoulders in the curve. This result revealed a second and a third distribution in the dry polymer. If the monomer and the dry polymer conversion values were considered, the dry polymer conversion of THFA was found to be much lower than that of BzA due to the loss of a portion of the resulting polymer during purification procedure (Table 1). This result was in agreement with the bigger shoulder of the lowest molecular weight chains in SEC result of THFA photopolymerization as compared to BzA. The monomer conversion values

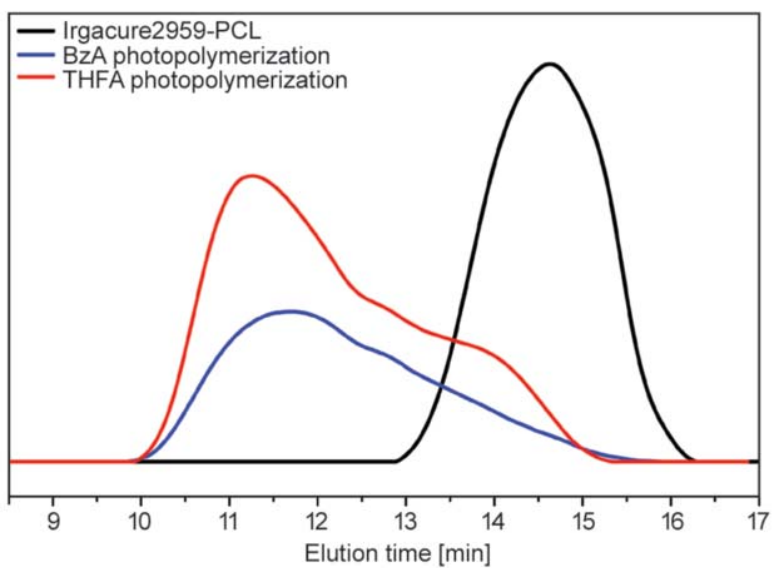

Figure 10. SEC results of the dry polymer after photopolymerization reactions performed by using BzA, THFA and the PCL based macrophotoinitiator

Table 1. The $M_{\mathrm{n}}$, PDI, monomer conversion, dry polymer conversion, $T_{\mathrm{g}}$ and $T_{\mathrm{m}}$ values of the macrophotoinitiator and the polymers obtained via photopolymerization of BzA, THFA, HEA and PEGMEA-480. * Monomer conversion was calculated from the ${ }^{1} \mathrm{H}$ NMR of the reaction mixtures after photopolymerization. ${ }^{* *}$ Measured by weighing.

\begin{tabular}{|c|c|c|c|c|c|c|c|c|}
\hline \multirow[b]{2}{*}{ Experiment } & \multirow{2}{*}{$\begin{array}{c}M_{\mathrm{n}}^{\text {SEC }} \\
{[\mathrm{g} / \mathrm{mole}]}\end{array}$} & \multirow[b]{2}{*}{ PDI } & \multirow{2}{*}{$\begin{array}{c}\text { Monomer } \\
\text { conv. } \\
{[\%]^{*}}\end{array}$} & \multirow{2}{*}{$\begin{array}{c}\text { Dry polymer } \\
\text { conv. } \\
{[\%]}\end{array}$} & \multicolumn{2}{|c|}{$T_{\mathrm{g}}$} & \multicolumn{2}{|c|}{$T_{\mathrm{m}}$} \\
\hline & & & & & $\begin{array}{c}T_{\mathrm{g}, 1} \\
{\left[{ }^{\circ} \mathbf{C}\right]}\end{array}$ & $\begin{array}{c}T_{\mathrm{g}, 2} \\
{\left[{ }^{\circ} \mathrm{C}\right]}\end{array}$ & $\begin{array}{l}T_{\mathrm{m}, 1} \\
{\left[{ }^{\circ} \mathrm{C}\right]}\end{array}$ & $\begin{array}{l}T_{\mathrm{m}, 2} \\
{\left[{ }^{\circ} \mathbf{C}\right]}\end{array}$ \\
\hline Ir2959-PCL & 5150 & 1.46 & - & 52 & -53.3 & - & 52.3 & \\
\hline BzA & 113000 & - & 90 & 93 & -6.5 & - & - & - \\
\hline THFA & 108000 & - & 94 & 73 & -12.2 & - & 52.4 & 56.7 \\
\hline HEA & - & - & - & $65^{* *}$ & -55.3 & 16.5 & 55.9 & 160 \\
\hline PEGMEA-480 & - & - & - & $48^{* *}$ & -61.2 & - & 6.6 & 54 \\
\hline
\end{tabular}


of BzA and THFA were calculated from the ${ }^{1} \mathrm{H}$ NMR results of the reaction mixtures of the photopolymerization products. It is noteworthy to mention that there was only one glass transition observed in the DSC thermogram of the photopolymerization product of BzA. Even though there was only one glass transition temperature was observed for BzA photopolymerization, the two slight shoulders at lower molecular weights in SEC curve might be the indication of homopolymers of PBzA and unreacted PCL. The PCL chains which were not functionalized with Ir2959 were not able to initiate the photopolymerization of the acrylates. Hence, the unreacted residues of homoPCL chains might have been recognized in DSC and SEC measurements.

\section{Conclusions}

The Ir2559 end-functionalized PCL based macrophotoinitiator was successfully synthesized via eROP. The macrophotoinitiator was further employed for the photopolymerization of the benzyl acrylate, tetrahydrofurfuryl acrylate, 2-hydroxyethyl acrylate and poly (ethylene glycol) methyl ether acrylate $\sim 480 \mathrm{~g} / \mathrm{mole}$. The photopolymerization reactions of benzyl acrylate and tetrahydrofurfuryl acrylate were found to be the most effective synthesis regarding the dry polymer conversions calculated form ${ }^{1} \mathrm{H}$ NMR results. On the other hand, PEG based macromonomer and 2-hydroxyethyl acrylate photopolymerizations eventualized with lower conversion values compared to BzA and THFA due to the dramatic viscosity increase during photopolymerization which resulted in gelation. Among the photopolymerization reactions, the best result was achieved with BzA regarding the conversion, thermal behaviour and SEC results, since there was only one $T_{\mathrm{g}}$ observed indicating the $100 \%$ amorphous strucuture. However, according to the SEC results, the photopolymerization product of BzA also had impurities possibly including the unreacted PCL and/or homopolymer of BzA. The light-induced polymerization of different acrylates showed that the enzymatic synthesis route of PCL based macrophotoinitiator as an efficient method to synthesize macrophotoinitiators.

\section{Acknowledgements}

N.U.K. thanks to Prof. Dr. Filip Du Prez, Asst. Prof. Dr. Nezha Badi, Benjamin Hendriks and Polymer Chemistry Research Group (Ghent University) as well as the Erasmus+ programme of the Turkish National Agency for financial support.

\section{References}

[1] Labet M., Thielemans W.: Synthesis of polycaprolactone: A review. Chemical Society Reviews, 38, 3484 3504 (2009).

https://doi.org/10.1039/b820162p

[2] Woodruff M. A., Hutmacher D. W.: The return of a forgotten polymer - Polycaprolactone in the $21^{\text {st }}$ century. Progress in Polymer Science, 35, 1217-1256 (2010). https://doi.org/10.1016/j.progpolymsci.2010.04.002

[3] Li Q., Li G., Yu S., Zhang Z., Ma F., Feng Y.: Ringopening polymerization of $\varepsilon$-caprolactone catalyzed by a novel thermophilic lipase from Fervidobacterium nodosum. Process Biochemistry, 46, 253-257 (2011). https://doi.org/10.1016/j.procbio.2010.08.019

[4] Albertsson A-C., Srivastava R. K.: Recent developments in enzyme-catalyzed ring-opening polymerization. Advanced Drug Delivery Reviews, 60, 1077-1093 (2008).

https://doi.org/10.1016/j.addr.2008.02.007

[5] Chatti S., Behnken G., Langanke D., Kricheldorf H. R.: Biodegradable polyesters based on cis-1,4-butenediol. Macromolecular Chemistry and Physics, 207, 14741484 (2006). https://doi.org/10.1002/macp.200600105

[6] Kricheldorf H. R.: Syntheses of biodegradable and biocompatible polymers by means of bismuth catalysts. Chemical Reviews, 109, 5579-5594 (2009). https://doi.org/10.1021/cr900029e

[7] Kobayashi S., Uyama H., Ohmae M.: Enzymatic polymerization for precision polymer synthesis. Bulletin of the Chemical Society of Japan, 74, 613-635 (2001). https://doi.org/10.1246/bcsj.74.613

[8] Yagci Y., Jockusch S., Turro N. J.: Photoinitiated polymerization: Advances, challenges, and opportunities. Macromolecules, 43, 6245-6260 (2010). https://doi.org/10.1021/ma1007545

[9] Fisher J. P., Dean D., Engel P. S., Mikos A. G.: Photoinitiated polymerization of biomaterials. Annual Review of Materials Research, 31, 171-181 (2001). https://doi.org/10.1146/annurev.matsci.31.1.171

[10] Degirmenci M., Hizal G., Yagci Y.: Synthesis and characterization of macrophotoinitiators of poly( $\varepsilon$-caprolactone) and their use in block copolymerization. Macromolecules, 35, 8265-8270 (2002).

https://doi.org/10.1021/ma020668t

[11] Degirmenci M., Urun T., Durgun M., Barim E.: Synthesis of mid-chain functional macrophotoinitiators of poly(D,L-lactide) homopolymer and tetrablock poly (D,L-lactide)-poly( $\varepsilon$-caprolactone) copolymer by ringopening polymerization. Designed Monomers and Polymers, 18, 669-677 (2015). https://doi.org/10.1080/15685551.2015.1070499

[12] Kobayashi S.: Recent developments in lipase-catalyzed synthesis of polyesters. Macromolecular Rapid Communications, 30, 237-266 (2009). https://doi.org/10.1002/marc.200800690 
[13] Yang Y., Yu Y., Zhang Y., Liu C., Shi W., Li Q.: Lipase/esterase-catalyzed ring-opening polymerization: A green polyester synthesis technique. Process Biochemistry, 46, 1900-1908 (2011).

https://doi.org/10.1016/j.procbio.2011.07.016

[14] Takwa M., Xiao Y., Simpson N., Malmström E., Hult K., Koning C. E., Heise A., Martinelle M.: Lipase catalyzed HEMA initiated ring-opening polymerization: In situ formation of mixed polyester methacrylates by transesterification. Biomacromolecules, 9, 704-710 (2008). https://doi.org/10.1021/bm7010449

[15] Takwa M., Hult K., Martinelle M.: Single-step, solventfree enzymatic route to $\alpha, \omega$-functionalized polypentadecalactone macromonomers. Macromolecules, 41, 5230-5236 (2008). https://doi.org/10.1021/ma800074a

[16] Düşü̈nkorur H. Ö., Pollet E., Phalip V., Güvenilir Y., Avérous L.: Lipase catalyzed synthesis of polycaprolactone and clay-based nanohybrids. Polymer, 55, 1648-1655 (2014). https://doi.org/10.1016/j.polymer.2014.02.016

[17] Córdova A.: Synthesis of amphiphilic poly( $\varepsilon$-caprolactone) macromonomers by lipase catalysis. Biomacromolecules, 2, 1347-1351 (2001).

https://doi.org/10.1021/bm0101015

[18] Faucher S.: Macro-photoinitiator via enzymatic polymerization. U.S. Patent 8507571 B2, USA (2013).

[19] Aparicio J. L., Elizalde M.: Migration of photoinitiators in food packaging: A review. Packaging Technology and Science, 28, 181-203 (2015).

https://doi.org/10.1002/pts.2099

[20] de Groot J. H., Dillingham K., Deuring H., Haitjema H. J., van Beijma F. J., Hodd K., Norrby S.: Hydrophilic polymeric acylphospine oxide photoinitiators/crosslinkers for in vivo blue-light photopolymerization. Biomacromolecules, 2, 1271-1278 (2001).

https://doi.org/10.1021/bm015584r
[21] Oberti T. G., Schiavoni M. M., Cortizo M. S.: Structure and properties of poly(benzyl acrylate) synthesized under microwave energy. Radiation Physics and Chemistry, 77, 597-604 (2008).

https://doi.org/10.1016/j.radphyschem.2007.09.015

[22] Mochizuki A., Hatakeyama T., Tomono Y., Tanaka M.: Water structure and blood compatibility of poly(tetrahydrofurfuryl acrylate). Journal of Biomaterials Science, Polymer Edition, 20, 591-603 (2009). https://doi.org/10.1163/156856209x426411

[23] Aran B., Sankır M., Vargün E., Sankır N. D., Usanmaz A.: Tailoring the swelling and glass-transition temperature of acrylonitrile/hydroxyethyl acrylate copolymers. Journal of Applied Polymer Science, 116, 628-635 (2010). https://doi.org/10.1002/app.30854

[24] Chen S., Hu T., Tian Y., Chen L., Pojman J. A.: Facile synthesis of poly(hydroxyethyl acrylate) by frontal free-radical polymerization. Journal of Polymer Science Part A: Polymer Chemistry, 45, 873-881 (2007). https://doi.org/10.1002/pola.21865

[25] Lowe S., O'Brien-Simpson N. M., Connal L. A.: Antibiofouling polymer interfaces: Poly(ethylene glycol) and other promising candidates. Polymer Chemistry, 6 , 198-212 (2015). https://doi.org/10.1039/c4py01356e

[26] Yagci Y., Sangermano M., Rizza G.: In situ synthesis of gold-cross-linked poly(ethylene glycol) nanocomposites by photoinduced electron transfer and free radical polymerization processes. Chemical Communications, 2008, 2771-2773 (2008). https://doi.org/10.1039/b803279c 